\title{
A imagem como veículo de
} traumas: por que fotografias ou vídeos de cenas de guerra provocam estresse pós-traumático em pessoas distantes dos locais onde ocorrem?

\author{
Leão SERVA \\ São Paulo, SP, Brasil.
}

Conflito de interesses: O autor declara não haver nenhum interesse profissional ou pessoal que possa gerar conflito de interesses em relação a este manuscrito.

\section{Resumo}

Este trabalho analisa as conclusões de estudos recentes sobre a ocorrência de Síndrome de Estresse Pós-Traumático em profissionais que lidam com imagens de conflitos distantes: controladores de voo de drones ou editores incumbidos de receber e editar fotografias em centros como Nova York, Londres ou Paris. $O$ estudo é realizado no contexto de pesquisa, feita com ferramentas de reconhecimento de emoções em expressões faciais, que visa a identificar os sentimentos que as imagens de guerra provocam. Segundo esse levantamento, o espectador manifesta crescente engajamento diante de uma sucessão de imagens, enquanto expressões de surpresa e repugnância iniciais diminuem. $O$ texto considera as imagens como veículos condutores da energia despertada pelas cenas originais, considerando que sua potência é preservada pela capacidade de reconhecimento dos sentimentos expressos pelas figuras retratadas, através de mecanismos que compõem a empatia, como os neurônios espelho, ou registros na memória profunda. $\bigcirc$ texto relaciona essa capacidade das imagens de preservar a energia das cenas originais com o conceito de "fórmulas de emoção", criado por Aby Warburg, para quem imagens arcaicas reprocessadas no presente provocam emoção imediata, por estarem impregnadas na memória coletiva (ou "memória social", como ele usou). Warburg baseou-se nos estudos de Richard Semon, criador do conceito de Mneme, apontado como um paralelo do conceito de "inconsciente coletivo" de Carl Jung.

\section{Descritores}

stress psicológico, fotografia, memória social, inconsciente coletivo.

Recebido: 3 out 2019; $1^{\text {a }}$ revisão: 7 out 2019; Aprovado: 22 out 2019; Aprovado para publicação: 13 nov 2019 


\title{
Images as carriers of trauma: Why do war photographs or videos cause post-traumatic stress in people far from places where they occur?
}

\begin{abstract}
This paper analyzes the findings of recent studies on the occurrence of PostTraumatic Stress Disease in Professionals dealing with distant conflict imagery: flight controllers working with drones or editors tasked with receiving and editing photographs in centers such as New York, London or Paris. The study is conducted in the context of research, made with tools of emotions recognition in facial expressions, which aims to identify the feelings that war images provoke. According to this survey, the viewer manifests increasing engagement in a succession of images, while expressions of initial surprise and disgust diminish. The text considers images as conducting vehicles of the energy aroused by the original scenes, considering that their power is preserved by the ability to recognize the feelings expressed by the portrayed images, through mechanisms that make up empathy, such as mirror neurons, or deep memory records. The text relates this ability of images to preserve the energy of the original scenes with the concept of "emotion formulas", created by Aby Warburg, for whom archaic images reprocessed in the present cause immediate emotion, because they are impregnated in collective memory (or "social memory" as he expressed it). He was inspired by the work of Richard Semon, creator of the concept of Mneme, idea considered a parallel to Carl Jung's concept of "collective unconscious".
\end{abstract}

Descriptors

psychological stress, photography, social memory, collective unconscious. 


\section{La imagen como vehículo de traumas: ¿Por qué las fotografías o videos de escenas de guerra causan estrés postraumático en personas lejos de los lugares donde ocurren?}

\section{Resumen}

Este artículo analiza los resultados de estudios recientes sobre la aparición de síndrome de estrés postraumático entre profesionales que manejan imágenes distantes de conflictos: controladores de vuelo de drones o editores encargados de recibir y editar fotografías en centros como Nueva York, Londres o París. El estudio se lleva a cabo en el contexto de una investigación realizada con herramientas para identificar emociones en las expresiones faciales, cuyo propósito es captar los sentimientos que desencadenan las imágenes de guerra. Según esta investigación, el espectador manifiesta una involucración cada vez mayor frente a una sucesión de imágenes, mientras se reducen las expresiones iniciales de sorpresa y repulsión. El texto considera las imágenes como vehículos conductores de la energía generada por las escenas originales, considerando que su poder puede conservarse mediante la capacidad de conciliar los sentimientos expresados por las figuras retratadas, a través de mecanismos que componen la empatía, como las neuronas espejo o registros de memoria profunda. El texto vincula esta capacidad de las imágenes para preservar la energía de las escenas originales con el concepto de "fórmulas de emoción" creado por Aby Warburg (1866-1929), por el cual las imágenes arcaicas reprocesadas en el presente causan emoción inmediata porque están imbuidas en la memoria colectiva (la "memoria social" como lo expresó). Warburg se inspiró en el trabajo de Richard Semon (1859-1918), creador del concepto de Mneme, idea que se considera paralela al concepto del "inconsciente colectivo" de Carl Jung.

\section{Descriptores}

estres psicológico, fotografía, memoria social, inconsciente colectivo. 


\section{Introdução}

Este trabalho se realiza no contexto de estudos sobre jornalismo de guerra e, mais particularmente, sobre o impacto das imagens de conflito sobre a audiência. Tendo coberto guerras civis na Bósnia, Croácia, Angola, Somália e Irlanda do Norte nos anos 1990, tenho me dedicado à análise da relação entre os espectadores e os conflitos, mediada e mediatizada pela imprensa. O fio condutor geral dos trabalhos que realizei em mestrado (Serva, 2001) e doutorado (Serva, 2017) é a tentativa de entender por que a cobertura de guerras, desde o seu nascimento na Guerra da Criméia (1853-1856), tem sido sempre uma poderosa alavanca de audiência, provocando de crescimento de circulação de jornais e espectadores de rádio e tevê, nos séculos XIX e XX, ao aumento do número de assinaturas de tevês pagas e websites mais recentemente.

Pergunto: por que plateias tão distantes de epicentros de conflito se interessam tanto pelos acontecimentos que pouco as influenciam, a ponto de gastar tempo e dinheiro para acompanhar o noticiário? $\bigcirc$ estudo, em desenvolvimento, que aqui descrevo busca explicar essa atração com base em reações neurais que as imagens despertam.

Na pesquisa doutoral "A 'fórmula da emoção' na fotografia de guerra" (Serva, 2017), procurou-se escrutar a reação do espectador às imagens violentas com base nos trabalhos do estudioso das imagens alemão Aby Warburg (1866-1929), que em estudos sobre a tradição antiga e medieval mostrou que, para expressar emoção em suas obras, os artistas do Renascimento reproduziam modelos pré-forjados na Antiguidade, que ele chamou de Pathosformel, ou "fórmulas de pathos" (Warburg, 2012). Depois de séculos da Idade Média, em que a arte fundamentalmente religiosa não expressava emoções, os pintores decalcavam imagens de obras gregas ou romanas que, tanto na época de origem como no Renascimento, provocavam emoção imediata, como ele mostraria, pelos mecanismos da empatia, que na mesma época estavam sendo desenvolvidos por Theodor Lipps (1851-1914).

Warburg e Carl Jung (1875-1961) foram contemporâneos e contemporâneos do criador do conceito de Mneme, Richard Semon (18591918), que os influenciou de formas diferentes. Aby Warburg (2012) concebeu o conceito de Pathosformel, ou fórmulas de emoção, como imagens arcaicas reprocessadas no presente que provocam emoções imediatas, por estarem impregnadas na memória coletiva (ou "memória social", como ele usou mais frequentemente). Ele se baseava nos estudos de Semon, atribuindo aos engramas (a menor unidade de memória impregnada no ser humano, conforme Semon, 1904, citado por Jung, 1982, p. 13, § 219) uma dimensão social: memórias coletivas são gravadas nos indivíduos de forma semelhante como ocorre com os elementos da memória individual. No texto que explica sua obra final, o "Atlas de imágens mnemosine", que ele deixou inacabado ao morrer em 1929, Warburg dizia que a criação artística "se vale da massa hereditária mnémica [sic] inalienável [...] para 
formar o estilo da obra de arte" (Warburg, 2012, p. 29). Mais adiante, ele diz:

Na região da exaltação orgiástica coletiva, se vai buscar a matriz que molda as formas expressivas da exaltação máxima interior da memória, até onde elas se deixem expressar em uma linguagem gestual com tal intensidade que estes engramas da experiência passional sejam capazes de sobreviver como patrimônio hereditário na memória (p. 43).

Embora Warburg jamais tenha escrito sobre o psicanalista suíço, há um "sugestivo paralelismo entre o sistema desenvolvido por Warburg e as ideias de Jung sobre os arquétipos e a memória racial" (Gombrich, 1992) (ou o inconsciente coletivo), como destaca E. H. Gombrich na biografia do pensador alemão. A proximidade (paralelo) de Warburg com o pensamento de Jung pode ser percebida também no fascínio dos dois pelo pensamento arcaico e pela tradição oriental, a paixão pela astrologia e seus mitos fundadores, o uso semelhante de termos, como símbolo, mas acima de tudo pela intensa dedicação ao estudo das imagens e seu impacto mais profundo do que o detectado pela razão.

Quanto à proximidade entre os conceitos de "memória social" e o de "inconsciente coletivo", aparece com clareza no seguinte trecho de Jung:

Devemos pensar nestas imagens como isentas de um conteúdo, sendo, portanto, inconscientes. Elas adquirem conteúdo, influência e por fim se tornam conscientes, ao encontrarem fatos empíricos que tocam a predisposição inconsciente, infundindo-lhe vida. Num certo sentido, são sedimentos de todas as experiências dos antepassados, mas não essas experiências em si mesmas [itálicos do original] (Jung, 1982, p. 66, § 300).

Em seguida, Jung (1982) faz referência ao conceito de Semon (1904):

Devo confessar que até agora não encontrei uma prova infalível da herança das imagens mnemônicas; em todo caso não posso assegurar a impossibilidade absoluta de que, ao lado desses sedimentos coletivos, desprovidos de qualquer caráter específico individual, possam ocorrer memórias hereditárias individualmente determinadas (Jung, 1982, p. 66, § 300).

\section{O impacto distante}

Desde o início do desenvolvimento de drones, entre o fim do século XX e o início do XXI, os militares norte-americanos têm aumentado o uso desses equipamentos teleguiados para telebombardear inimigos em cantos distantes do planeta. Evidentemente, seu objetivo é aumentar a capacidade de ataques táticos reduzindo riscos de vítimas, uma vez que os drones são 
comandados por militares posicionados em salas instaladas em Houston, no Texas, a meio mundo de distância do local da grande maioria dos ataques, entre o Oriente Médio e o subcontinente indiano. Esses técnicos comandam as aeronaves através de telas semelhantes às de tevês, com equipamentos muito semelhantes aos de videogames. Só o que vêm são imagens captadas por câmeras no avião.

Por toda a proteção garantida pela distância, foi surpreendente para os comandantes militares do país constatar que os pilotos de drones padeciam de Síndrome de Estresse Pós-Traumático semelhante ao que acometia os pilotos de aviões bombardeiros diretamente engajados em combates no front, embora em proporções menores $(4,3 \%$, contra $10 \%$ a $18 \%$, segundo Blaszczak-Boxe, 2014).

Algo semelhante acontece na imprensa: os escritórios das principais agências de notícias e veículos jornalísticos localizados em Nova York, Londres, Paris e outras cidades a milhares de quilômetros dos locais em conflito, recebem as inúmeras imagens enviadas por repórteres engajados diretamente em coberturas no front, que testemunham e fotografam os combates, as explosões, as vítimas etc. Nos últimos anos, houve um desenvolvimento grande dos estudos sobre o Estresse Pós-Traumático em jornalistas, um campo de pesquisas bastante recente, iniciado pelo médico canadense Anthony Feinstein em 2003, como consequência das guerras iniciadas após o ataque às Torres Gêmeas, em 2001.

Feinstein foi chamado para atender um caso estranhíssimo de uma mulher que sofria de uns aparentes ataques, com todos os sintomas de acidente vascular cerebral (AVC), era levada ao hospital e logo ao chegar, melhorava. Depois que isso aconteceu uma segunda e uma terceira vez, seu neurologista achou que podia se tratar de um caso psicológico e a encaminhou para Feinstein. Logo ao conhecê-la e saber que se tratava de uma repórter de TV canadense recém-retornada de uma experiência de cobertura de guerra, o médico intuiu que poderia se tratar de um caso de estresse traumático e buscou a literatura sobre essa ocorrência entre jornalistas e pessoal de mídia, e descobriu que não havia qualquer estudo: os jornalistas não narravam seus estresses e as empresas tampouco detectavam ou reportavam esse tipo de ocorrência. Desde então, Feinstein (2006) escreveu alguns livros e artigos e despertou um sem número de pesquisas sobre o assunto. 
Pouco depois disso, ao fazer o curso de segurança para correspondentes em áreas de risco da empresa britânica Centurion Risk Assessment vi que esses estudos já estavam mudando a visão sobre a profissão e seus riscos. Se nos anos 1990 a preocupação com a segurança dos repórteres visava a protegê-los fisicamente, desde o início dos anos 2000 ganharam relevância o preparo e a proteção psicológica. Foi ali que aprendi que profissionais de mídia são a terceira categoria mais exposta ao estresse pós-traumático, após os militares e os profissionais da área de saúde: ao todo, um terço dos jornalistas envolvidos em coberturas de guerras sofrem de estresse póstraumático (Taibi, 2015).

Todos esses estudos ajudaram muito os jornalistas no front. Atualmente, uma série de providências têm sido tomadas para reduzir o risco de que os repórteres envolvidos em coberturas de conflitos sofram traumas que possam deixar sequelas em sua saúde mental. Um fotógrafo de agência noticiosa, por exemplo, trabalha três semanas em áreas de conflito, com descanso e folgas nesse período e em seguida é obrigado a passar um mês de férias em casa.

Foi, portanto, surpreendente para os gestores de companhias noticiosas constatar que os editores de fotografias incumbidos de receber as fotografias nas cidades distantes apresentam os mesmos sinais de Estresse PósTraumático que os fotógrafos no front. Ou seja, mesmo à distância e sem envolvimento direto com a cena, a imagem transporta a emoção correspondente.

O senso comum e estudos anteriores sempre consideraram a fotografia e as imagens em geral como formas de transmissão de informações visuais e, coerentes com a teoria da informação tradicional (Shannon \& Weaver, 1949), ao longo do circuito de comunicação haveria uma perda de intensidade, ou entropia. A imagem visual, portanto, reduziria o impacto da visão direta do objeto. Mas não é nada disso o que se vê: os estudos sobre estresse entre pilotos que se relacionam apenas com imagens das cenas de guerra ou com editores que têm por profissão selecionar fotos de guerra mostram que as imagens transportam a energia da cena retratada.

Neste texto quero argumentar que a imagem deve ser considerada como a própria emoção por conter em si os elementos necessários para que o observador, mesmo longínquo, viva integralmente a experiência da testemunha in loco. 
Quando vivemos um episódio impactante, dolorido ou trágico, de alguma forma traumático, nosso organismo reage com uma cadeia de reações químicas: certas substâncias são secretadas e rapidamente percorrem os nossos nervos levando uma carga elétrica da periferia ao cérebro.

Em resumo, se eu dou uma martelada no dedo, uma descarga elétrica vai percorrer a distância entre o dedo e o cérebro em uma velocidade semelhante à da luz, o que para quase todos os efeitos é igual a dizer "no mesmo instante", "simultaneamente". Essa descarga é tão forte que congela todos os outros sentidos do organismo: o estômago para de digerir, os olhos param de ver o que não seja aquilo, o pensamento suspende todas os demais raciocínios em curso e, algumas vezes, até a memória é suspensa. Podemos dizer que o tempo para nesse instante, até que ele seja superado.

Algo semelhante acontece com a zebra que distraidamente pasta na grande planície do Seringeti, semelhante à que vemos no filme "Rei Leão", e subitamente nota a presença a poucos metros de seu pescoço de um leão, o terrível predador, pulando em seu dorso para dar uma mordida. Naquele exato instante, no corpo da zebra, uma grande quantidade de adrenalina é despejada na corrente sanguínea de tal forma que, para todos os efeitos, corresponde a uma descarga elétrica: ela suspende o tempo e sem mesmo entender o que está fazendo, sai correndo. Não importa nem mesmo se na mordida o leão já levou uma parte de sua barriga, que pode estar sangrando em profusão; a adrenalina suspende também a sensação de dor. A zebra corre numa velocidade maior do que é possível imaginar por todas as outras oportunidades em que correu na vida até então (Sapolsky, 2000). A visão real do leão desperta na zebra esse trauma que vai perdurar até que ela morra ou escape.

Todos sabem que se dermos uma martelada no dedo isso vai doer muito, certo? Isso que para o leigo é uma "imensa dor", para o neurologista é um impulso elétrico que percorre o corpo, do local da pancada até o cérebro em uma velocidade semelhante à da luz, o que para todos os efeitos é igual a "simultaneamente", "ao mesmo tempo". Bato o martelo no dedo e imediatamente meu cérebro é informado por uma descarga elétrica. Vejo um leão se aproximando de meu cangote, imediatamente vivo uma descarga elétrica semelhante. Com equipamentos de monitoramento da atividade cerebral, é possível detectar os impulsos elétricos chegando a certas regiões do cérebro em casos de intensa ação da adrenalina, por exemplo.

Em 1992, uma equipe de neurocientistas da Universidade de Parma, liderada pelo italiano Vittório Gallese, descobriu uma coisa fascinante: 
quando uma pessoa observa uma outra pessoa tendo uma experiência que ela reconhece, seu cérebro vivencia os mesmos impulsos que o da outra pessoa. A isso, o cientista italiano chamou de "neurônios espelho" (Gallese \& Goldman, 1998). Na experiência, realizada na Universidade de Parma, foram instalados sensores que captavam os disparos de neurônios de um macaco e os projetavam em uma tela de computador, mostrando exatamente que áreas do cérebro foram ativadas em função de ações vivenciadas pelo indivíduo.

Quando o macaco apanhava um amendoim da mão do experimentador, o neurônio emitia um breve estouro que, amplificado, soava como uma metralhadora. Instantes depois, o macaco observava o experimentador apanhar um amendoim e a mesma célula voltava a disparar. Dessa vez, no entanto, ela o fazia em resposta à ação de outro indivíduo. $\bigcirc$ que torna esses neurônios especiais é a ausência de distinção entre 'macaco vê' e 'macaco faz' (De Wall, 2010, p. 117).

Ou seja, os impulsos cerebrais são iguais tanto no indivíduo que tomou a martelada quanto no que assistiu a cena.

O que Gallese chamou de "neurônios espelho" (aqueles que são ativados pela visão do outro, pois eles refletem a energia que atuou nos neurônios do primeiro indivíduo) explicou a neurologia da empatia (Gallese \& Goldman, 1998): ela não é uma decisão consciente e refletida, é algo corpóreo e irrefletido, imediato. $O$ termo empatia havia sido criado por Theodor Lipps (1851-1914) no começo do século XX, compondo uma expressão a partir do grego empatheia, que significa "experimentar forte afeto ou paixão" (DE WAAL, 2010). Mas em alemão a expressão é traduzida por Einfühlung (sentir em), que transmite a ideia do indivíduo sentindo algo que está em outro. E essa denotação corresponde literalmente ao que Gallese viria descobrir quase cem anos depois: sentimos em nós mesmos de fato e integralmente o que o outro sente (Gallese \& Goldman, 1998).

Seguindo nesse raciocínio, inúmeros estudos têm demonstrado que a empatia ocorre também diante da visão de fotografias. Estas pesquisas, como as realizadas pela neurologista belga Beatrice de Gelder (2006), mostram que as pessoas reconhecem de forma imediata o sentimento dos outros, especialmente à visão de seu rosto, mas também diante dos gestos de seu corpo. E isso ocorre mesmo quando o outro está em uma fotografia.

A consequência do reconhecimento do sentimento de uma outra pessoa é a contaminação do observador pelo estado emocional do observado. De 
Waal (2010) menciona como exemplo do reconhecimento imediato a reação a uma postura amedrontada, que ele descreve: "O corpo todo pronto para a fuga, e as mãos tentando repelir o perigo" (p. 119). $\bigcirc$ observador terá medo automaticamente.

Em outras palavras, a empatia funciona como os efeitos descritos por Gallese em seus estudos dos "neurônios espelho" e é despertada diante da visão de pessoas e, também, de fotografias (Gallese \& Goldman, 1998).

Isso nos remete aos estudos do especialista em cultura alemã Aby Warburg (1866-1929), para quem ao transportar emoções, a imagem, seja ela de qual natureza for, deve ser reconhecida como um "dinamograma" (Warburg, 2012, p. 29), um registro de energia (dínamo, que quer dizer força, poder, em grego), contida na cena ou, também é igual, da energia que ela desperta no observador. Para Warburg (2012), a imagem é como uma bateria que contém a energia, não é apenas um modelo abstrato, um desenho de formas externas ou superficiais do objeto.

E esse conceito pode assim explicar com maior clareza a razão pela qual a imagem pode ser veículo de traumas, uma vez que ela é a expressão de toda a energia, frequentemente trágica, eventualmente traumática, da cena retratada. Segundo essa concepção, a fotografia contém a própria essência da cena retratada e não só a sua aparência.

\section{Referências}

Blaszczak-Boxe, A. (2019, 20 August). Drone pilots suffer PTSD just like those in combat. LiveScience. Recuperado de https://www.livescience.com/47475-drone-operators-develop-ptsd.html.

De Gelder, B. (2006). Towards the neurobiology of emotional body language. Nature Reviews Neuroscience, 7,(3), 242-249. https://doi.org/10.1038/nrn1872.

De Waal, F. (2010). A era da empatia. São Paulo: Companhia das Letras.

Feinstein, A. (2006). Journalists under fire: the psychological hazards of covering war. Baltimore: JHU Press.

Gallese, V., \& Goldman, A. (1998). Mirror neurons and the simulation theory of mind-reading. Trends in cognitive sciences, 2,(12), 493-501. https://doi.org/10.1016/S1364-6613(98)01262-5.

Gombrich, E. H. (1992). Aby Warburg: una biografía intelectual. Madrid: Alianza Forma. 
Jung, C. G. (1982). O eu e o inconsciente (Obras completas, Vol. VII/2). Petrópolis, RJ: Vozes.

Sapolsky, R. M. (2000). Why zebras don't get ulcers: the acclaimed guide to stress, stress-related diseases, and coping. New York: Barnes \& Noble Books.

Serva, L. (2001). Jornalismo e desinformação. São Paulo: Senac.

Serva, L. (2017). A "fórmula da emoção" na fotografia de guerra: como as imagens de conflitos se relacionam com a tradição iconográfica explorada por Aby Warburg (Tese de doutorado, Comunicação e Semiótica, Pontifícia Universidade Católica de São Paulo.

Shannon, C. E., \& Weaver, W. (1949). A mathematical model of communication. Urbana, IL: University of Illinois Press.

Taibi, C. (2015). It's not just war reporters: how viewing graphic content secondhand can lead to Mental Health Issues in Journalists. Huffington Post. Recuperado de https://www.huffpostbrasil.com/2015/05/19/secondhand-traumajournalists_n_7305992.html.

Walburg, A. (2012). El atlas de imágenes Mnemosine (L. Baez Rubi, org., Vol. 2). México, D.F.: Universidad Nacional Autónoma de México.

Minicurrículo: Leão Serva - Diretor de Jornalismo da TV Cultura. Mestre e doutor em Comunicação e Semiótica pela PUC-SP e pós doutorando em Neuroestética das Imagens pela ESPM-SP. É autor de "Jornalismo e Desinformação" (Senac) e "A Fórmula da Emoção na Fotografia de Guerra" (no prelo).E-mail: leao.serva@gmail.com 